\title{
"Investigação em Didáctica e Ensino das Ciências: Percepções dos Professores de Física e Química"
}

Dissertação apresentada em 1997, por Célia Maria Costa Lopes, da Escola Secundária da Gafanha da Nazarél, sob a orientação de Isabel P. Martins.

Embora recente como Ciência a Didáctica reúne já um número muito avultado de resultados emergentes da investigação os quais são considerados por investigadores $\mathrm{e}$ alguns professores dos vários níveis de ensino, relevantes para efeitos de tomada de decisão sobre práticas de ensino.

Os estudos de investigação realizados na última década, centrados em questões de sala de aula, indicam que subjacente às práticas dos professores existem epistemologias, normalmente empiristas, e psicopedagogias essencialmente behavioristas, que orientam as opções didácticas (por exemplo, selecção de conteúdos de ensino e a escolha de estratégias/metodologias de ensino), condicionando as próprias aprendizagens dos alunos sobre Ciência e acerca da Ciência.

Sendo reconhecido que apesar dos esforços dispendidos pelos investigadores as mudanças didácticas prospectivadas estão longe da consolidação desejada, propusemo-nos averiguar possíveis razões que estarão na base da separação existente entre a investigação em Didáctica e as práticas dos professores de Física e Química.

No estudo levado a cabo, de natureza empírica e de carácter descritivo, utilizou-se, como instrumento de recolha de dados, um questionário escrito construído para o efeito.

A amostra é constituída por 83 professores do Continente e das Regiões Autónomas. Em termos gerais, caracteriza-se por uma dominância do sexo feminino $(70 \%)$. com idades compreendidas entre os 25 e os 40 anos $(60 \%)$. As habilitações académicas mais representativas são a licenciatura em Ensino de Física e Quí-mica/Química ou Física Ramo Educacional $(60 \%)$ e o tipo de profissionalização dominante é, consequentemente, o estágio integrado $(60 \%)$. A experiência profissional dos inquiridos situa-se, predominantemente, entre 6 a 15 anos.

Os resultados obtidos permitiram-nos concluir que apesar dos professores considerarem possuir conhecimento sobre alguns dos temas desenvolvidos e objecto de investigação em Didáctica das Ciências (em particular sobre ${ }^{2}$, Concepções Alternativas, Resolução de Problemas, Análise de Manuais Escolares, Trabalho Experimental, Reforma Curricular e Ensino das Ciências/Química e Modelos de EnsinoAprendizagem), e que este conhecimento era importante para as suas práticas de ensino, em geral, não conseguiram justificar tal pertinência e/ou influência. Foi notória a insatisfação dos professores inquiridos sobre o seu próprio conhecimento nas temáticas afloradas, alegando, a maioria, uma formação inicial insuficiente nessas áreas. Destaca-se, em particular, a dificuldade manifestada na interpretação de propostas didácticas recentes emergentes da investigação, assim como o desconhecimento de fontes de informação escrita onde são divulgados grande número de estudos.

\section{ALGUMAS REFERÊNCIAS USADAS NESTE TRABALHO:}

CAAMANÕ, A. (1995) - " La Educacion Ciencia-Tecnologia-Sociedad: Una Necessidad en el Diseño del Nuevo Curriculum de Ciências" Alambique: Didáctica de las Ciencias Experimentales, 3: 6-12

\section{CARVALHO, A. M. e GIL- PÉREZ, D. (1995) - Formação de Pro- fessores de Ciências, Questões da Nossa Época, 26, 2a Edição, Cortez Editora, São Paulo \\ GARNETT, P. J., GARNETT, P. J. e HACKLING, M. W. (1995) - “ Student's Alternative Conceptions in Chemistry: A Review of Research and Implications for Teaching and Learning", Studies in Science Educati- on, 25: 69-95 \\ GIL-PÉREZ, D. (1996) - " New Trends in Science Education", Inter- national Journal of Science Education, 18 (8): 889-901 \\ HASHWEH, M. Z. (1996) - “ Effects of Science Teachers' Episte- mological Beliefs in Teaching", Jour- nal of Teacher Education, 44 (1): 5-15 \\ PEDRETTI, E. E HODSON, D. (1995) - "From Rhetoric to Action: Implementing STS Education Through Action Research", Journal of Research in Science Teaching, 32 (5): 463-485 \\ AGRADECIMENTO: \\ Manifesta-se publicamente o nosso agradecimento a todos os professores que generosamente aceitaram participar no estudo, res- pondendo ao questionário. \\ Rua: Dr António Vilào - Gafanha da Nazaré 3830 Gafanha da Nazaré} como sendo menos conhecidos: Ensino das Ciências/Química Assistido por Computador; Representaçào do Conhecimento Científico (por ex: mapa de conceitos); A Epistemologia/História e o Ensino das Ciências/Química; Dimensão CTS no Ensino das Ciências/Química: Linguagem Metafórica/ Analógica no Ensino das Ciências/Química. 